\title{
Thyroid-specific ablation of the Carney complex gene, PRKAR1A, results in hyperthyroidism and follicular thyroid cancer
}

\author{
Daphne $R$ Pringle ${ }^{1}$, Zhirong Yin ${ }^{1, t}$, Audrey A Lee ${ }^{1}$, Parmeet K Manchanda ${ }^{1}$, \\ Lianbo $\mathrm{Yu}^{2}$, Alfred $F$ Parlow ${ }^{3}$, David Jarjoura ${ }^{2}$, Krista M $D$ La Perle ${ }^{4}$ and \\ Lawrence S Kirschner ${ }^{1,5}$
}

\footnotetext{
${ }^{1}$ Department of Molecular, Virology, Immunology, and Medical Genetics, The Ohio State University, 420 West 12th Avenue, Tzagournis Research Facility 544, Columbus, Ohio 43210, USA

${ }^{2}$ Center for Biostatistics, The Ohio State University, Columbus, Ohio 43210, USA

${ }^{3}$ National Hormone and Peptide Program, Harbor-UCLA Medical Center, Torrance, California 90509, USA

${ }^{4}$ Department of Veterinary Biosciences, The Ohio State University, Columbus, Ohio 43210, USA

${ }^{5}$ Division of Endocrinology, Diabetes and Metabolism, The Ohio State University, 420 West 12th Avenue, Tzagournis Research

Facility 544, Columbus, Ohio 43210, USA

(Correspondence should be addressed to L S Kirschner at Department of Molecular, Virology, Immunology, and Medical Genetics, The Ohio State University; Email: lawrence.kirschner@osumc.edu)

${ }^{\dagger} \mathrm{Z}$ Yin is now at Department of Otolaryngology, Vanderbilt University, Nashville, Tennessee 37232, USA
}

\begin{abstract}
Thyroid cancer is the most common endocrine malignancy in the population, and the incidence of this cancer is increasing at a rapid rate. Although genetic analysis of papillary thyroid cancer (PTC) has identified mutations in a large percentage of patients, the genetic basis of follicular thyroid cancer (FTC) is less certain. Thyroid cancer, including both PTC and FTC, has been observed in patients with the inherited tumor predisposition Carney complex, caused by mutations in $P R K A R 1 A$. In order to investigate the role of loss of PRKAR1A in thyroid cancer, we generated a tissue-specific knockout of Prkar1a in the thyroid. We report that the resulting mice are hyperthyroid and developed follicular thyroid neoplasms by 1 year of age, including FTC in over $40 \%$ of animals. These thyroid tumors showed a signature of pathway activation different from that observed in other models of thyroid cancer. In vitro cultures of the tumor cells indicated that Prkar1a-null thyrocytes exhibited growth factor independence and suggested possible new therapeutic targets. Overall, this work represents the first report of a genetic mutation known to cause human FTC that exhibits a similar phenotype when modeled in the mouse. In addition to our knowledge of the mechanisms of human follicular thyroid tumorigenesis, this model is highly reproducible and may provide a viable mechanism for the further clinical development of therapies aimed at FTC.
\end{abstract}

Endocrine-Related Cancer (2012) 19 435-446

\section{Introduction}

Epithelial thyroid cancer (i.e. nonmedullary thyroid cancer) is the most common endocrine malignancy in the general population and rates of thyroid cancer continue to rise in the United States beyond what has been predicted from improved case ascertainment (Aschebrook-Kilfoy et al. 2010). Well-differentiated nonmedullary thyroid cancer is divided into papillary thyroid cancer (PTC) and follicular thyroid cancer (FTC) based on histological criteria. Although PTC is the more common subtype, patients with FTC have a poorer prognosis owing to the tendency of this tumor to behave more aggressively, including local and vascular invasion and distant metastases (Besic et al. 1999). 
Although there is a wealth of information regarding the molecular basis of PTC (reviewed in Nikiforov (2011)), less is known about the genetics of FTC. Analysis of sporadic tumors has identified mutations in $R A S$ in a small subset of tumors, whereas other investigators have demonstrated activating fusions between the PAX8 and PPARG transcription factors (Lacroix et al. 2005, Niepomniszcze et al. 2006). As $P A X 8$ is required for thyroid development, it has been hypothesized that the PPARG-PAX8 fusion protein causes cancer by activating aberrant gene transcription.

Analysis of genetic syndromes that include FTC is another potential source for the identification of the molecular mechanisms contributing to carcinogenesis. FTC is associated with two tumor predisposition syndromes, Carney complex (CNC) and Cowden syndrome (CS). CNC (OMIM \#160980) is characterized by spotty skin pigmentation, myxomas, endocrine tumors, and schwannomas (Stratakis et al. 2001). In a recent large series, benign thyroid adenomas were observed in $25 \%$ of cases, and thyroid cancer, either PTC or FTC or both, was found in $2.5 \%$ of patients, including being the cause of death in one patient (Bertherat et al. 2009). CNC is caused by inactivating mutations in PRKARIA (Kirschner et al. 2000), which encodes the type 1a regulatory subunit of the cAMP-dependent protein kinase (protein kinase A, PKA), and mutations of this gene have been observed in sporadic cases of thyroid cancer (Sandrini et al. 2002). CS (OMIM \#158350) is characterized as a multiple hamartoma syndrome and includes brain and breast cancer in addition to FTC. This syndrome is caused by inactivating mutations in PTEN, a dualspecificity phosphatase that negatively regulates the PI3 kinase/AKT pathway. Mutations in this gene have been detected in a variety of advanced sporadic cancers (reviewed in Hollander et al. (2011)) and in $\sim 5 \%$ of FTCs (Nagy et al. 2011).

Our laboratory has been interested in studying the mechanism of tumorigenesis associated with mutations in PRKARIA and its mouse homolog Prkarla. We have previously reported that Prkarla $^{+/-}$mice are prone to tumors in cAMP-responsive tissues, including the thyroid (Kirschner et al. 2005). Tissue-specific deletion of Prkarla in cAMP-responsive tissues such as GH-producing pituitary cells and Schwann cells can result in benign tumorigenesis associated with increased intracellular PKA activity (Jones et al. 2008, Yin et al. 2008b).

In this paper, we sought to extend these observations by generating a tissue-specific knockout (KO) of Prkarla in the thyroid. We demonstrate that loss of Prkarla in the thyroid gland leads to thyroid hyperfunction and the formation of FTC. This new model of FTC adds to our understanding of the molecular mechanisms involved in FTC development and may help to guide the development of new therapies.

\section{Materials and methods}

\section{Animal studies}

Mice were maintained in a sterile environment under $12 \mathrm{~h}$ light: $12 \mathrm{~h}$ darkness cycles, and animal experiments were carried out in accordance with the highest standards of animal care under an IACUCapproved protocol. The generation of Prkarla $a^{\text {loxP/loxP }}$ and thyroid peroxidase-cre (Tpo-cre) animals has been described (Kusakabe et al. 2004, Kirschner et al. 2005). PrkarlaloxP/loxP and Tpo-cre mice were mated in order to generate Tpo-cre; Prkarla ${ }^{\text {loxP/loxP }}$ (Rla-TpoKO) mice.

\section{Histology}

Immunohistochemistry experiments were performed as described previously (Jones et al. 2008) with the following antibodies: Akt (9272), pAkt ${ }^{\text {Ser473 }}$ (3787), Erk1/2 (Mapk1, Mapk3) (EPHB2) (9102), pErk $^{\text {Thr202/Tyr204 }}$ (9101), and cleaved caspase 3 (9661) (Cell Signaling Technology, Danvers, MA, USA); and Ki-67 (550609) (BD Biosciences, San Jose, CA, USA).

\section{Western blotting}

Proteins from mouse tissues were prepared and run on SDS-PAGE gels and transferred to nitrocellulose, blocked with $5 \%$ nonfat dry milk or BSA, and probed with the indicated antibodies. Antibodies used in this study were as follows: Akt (9272), pAkt ${ }^{\mathrm{Ser} 473}$ (9271), Erk1/2 (Mapk1, Mapk3) (9102), pErk ${ }^{\text {Thr202/Tyr204 }}$ (9101), pStat3 ${ }^{\text {Tyr705 }}$ (9145P), Stat3 (9132), pCreb ${ }^{\text {Ser133 }}$ (9198), and Creb (9197) (Cell Signaling Technology); Pcna (sc-56) and Spot14 (Thrsp) (sc-137178) (Santa Cruz Biotechnology, Santa Cruz, CA, USA); $\beta$-actin (A5060) (Sigma); and Tshr (250898) (Abbiotec, San Diego, CA, USA).

\section{Microarray}

RNA was isolated from the thyroids of 1-year-old wild-type (WT) and Rla-TpoKO mice using the Qiagen miRNeasy kit according to the manufacturer's instructions (Qiagen). cDNA was made using the Bio-Rad iScript cDNA Synthesis Kit (Bio-Rad Laboratories). cDNA samples were hybridized to the Affymetrix Mouse Exon 1.0 ST Array Chip 
(Affymetrix, Santa Clara, CA, USA). Pathways were analyzed using Ingenuity Pathways Analysis Software (IPA; Ingenuity Systems, www.ingenuity.com).

\section{Quantitative real-time PCR}

RNA was isolated from mouse thyroids or cultured RIa-TpoKO cells and converted to cDNA with the BioRad iScript cDNA Synthesis Kit (Bio-Rad Laboratories). cDNA was subject to qRT-PCR using the iQ SYBR Green Supermix Kit (Bio-Rad Laboratories) as per the manufacturer's instructions. Reactions were each performed in triplicate. Primers were as follows: androgen receptor $(A r)$ : 5'-GGACCATGTTTTACCCATCG, 3'TCGTTTCTGCTGGCACATAG; uncoupling protein 1 (Ucpl): 5'-GGGCCCTTGTAAACAACAAA, 3'-GTCGGTCCTTCCTTGGTGTA; $C 3$ : 5'-AAGCATCAACACACCCAACA, 3'-CTTGAGCTCCATTCGTGACA; Bcl3: 5'-TTACTCTACCCCGACGATGG, 3'-CCAAGCTTGAAAAGGCTGAG; Nfil3: 5'-CGGAAGTTGCATCTCAGTCA, 3'-GCAAAGCTCTCCAACTCCAC; Icaml: 5'-AGCACCTCCCCACCTACTTT, 3'-AGCTTGCACGACCCTTCTAA.

\section{Primary cell culture}

Primary culture of thyroid cells was performed as described previously (Jeker et al. 1999). Briefly, cells were cultured on poly-D-lysine-coated plates in 5\% fetal bovine serum in F12 media supplemented with L-glutamine, nonessential amino acids, sodium bicarbonate, and $6 \mathrm{H}$ hormone mix (TSH, insulin, hydrocortisone, glycyl-histidyl-L-lysine, transferrin, and somatostatin). All experiments were performed on cells through passage 20 or less. Inhibitors used were as follows: $10 \mu \mathrm{M}$ LY294002 and $10 \mu \mathrm{M}$ U0126 (Cell Signaling Technology); and $5 \mu \mathrm{M}$ myristoylated PKI (Invitrogen), $10 \mu \mathrm{M} \mathrm{HO}-3867$ (the generous gift of Dr P Kuppusamy, The Ohio State University). Cells were incubated in the presence of indicated inhibitors or media for $48 \mathrm{~h}$ (fresh inhibitors were added every $24 \mathrm{~h}$ ), followed by MTT assays performed using the MTT Cell Proliferation Assay Kit (Cayman Chemical, Ann Arbor, MI, USA) according to the manufacturer's instructions. All experiments were performed in triplicate.

\section{Statistical analysis}

All data, except microarray results, were analyzed via Student's $t$-test using StatCrunch Software (www. statcrunch.com); $P$ values $<0.05$ were considered significant.
For microarray results, signal intensities were quantified by Affymetrix software. Background correction and quantile normalization were performed to adjust technical bias, and gene expression levels were summarized using the RMA method (Irizarry et al. 2003). A filtering method based on percentage of arrays above noise cutoff was applied to filter low expression genes. A linear model was used to detect differentially expressed genes. In order to improve the estimates of variability and statistical tests for differential expression, a moderated t-statistic with variance smoothing was used for this study (Sartor et al. 2006, Yu et al. 2011). The significance level was adjusted by controlling the mean number of false positives (Gordon et al. 2007).

\section{Results}

\section{Deletion of Prkar1a in the thyroid results in hyperthyroidism and follicular thyroid neoplasia}

In order to generate a thyroid-specific deletion of Prkarla, we crossed mice harboring the Tpo-cre transgene with PrkarlaloxP/loxP animals to obtain Tpo-cre; Prkarla ${ }^{\operatorname{lox} P / l o x P}$ animals, hereafter referred to as Rla-TpoKO. Rla-TpoKO mice and WT littermates were followed up to 1 year of age and then killed. Blood was collected for analysis of thyroid function, and the thyroids were harvested for gross and histological examination. Thyroid hormone $\left(\mathrm{T}_{4}\right)$ levels in the Rla-TpoKO mice $(n=12)$ were markedly elevated compared with the controls $(n=12)$ (8.3 $\pm 4.4 \mu \mathrm{g} / \mathrm{dl}$ for $\mathrm{KO}$ vs $3.2 \pm 1.1 \mu \mathrm{g} / \mathrm{dl}$ in WT, $P=0.0009$ ), indicating biochemical hyperthyroidism. TSH levels were also measured and were found to be lower in the Rla-TpoKO mice $(157.25 \pm 54.13 \mathrm{ng} / \mathrm{ml}$ in $\mathrm{KO}$ vs $353 \pm 640 \mathrm{ng} / \mathrm{ml}$ in WT), although the differences were not statistically significant due to wide variations in the WT. While it is somewhat surprising that TSH levels were not significantly suppressed in these animals, it is a reasonable result given the relatively reduced sensitivity of the assay at the low end of the measurement range. To further show functional hyperthyroidism in these animals, body weights of WT and Rla-TpoKO animals at 1 year were compared. Although RIa-TpoKO females $(n=5)$ were on average smaller than their WT counterparts $(n=5)$ $(28.75 \pm 6.32 \mathrm{~g}$ for $\mathrm{KO}$ vs $37.91 \pm 8.87 \mathrm{~g}$ for WT, $P=0.0968)$, the difference did not reach statistical significance. However, these data along with the elevated $\mathrm{T}_{4}$ levels in these animals lead us to conclude that the Rla-TpoKO animals are functionally hyperthyroid. 

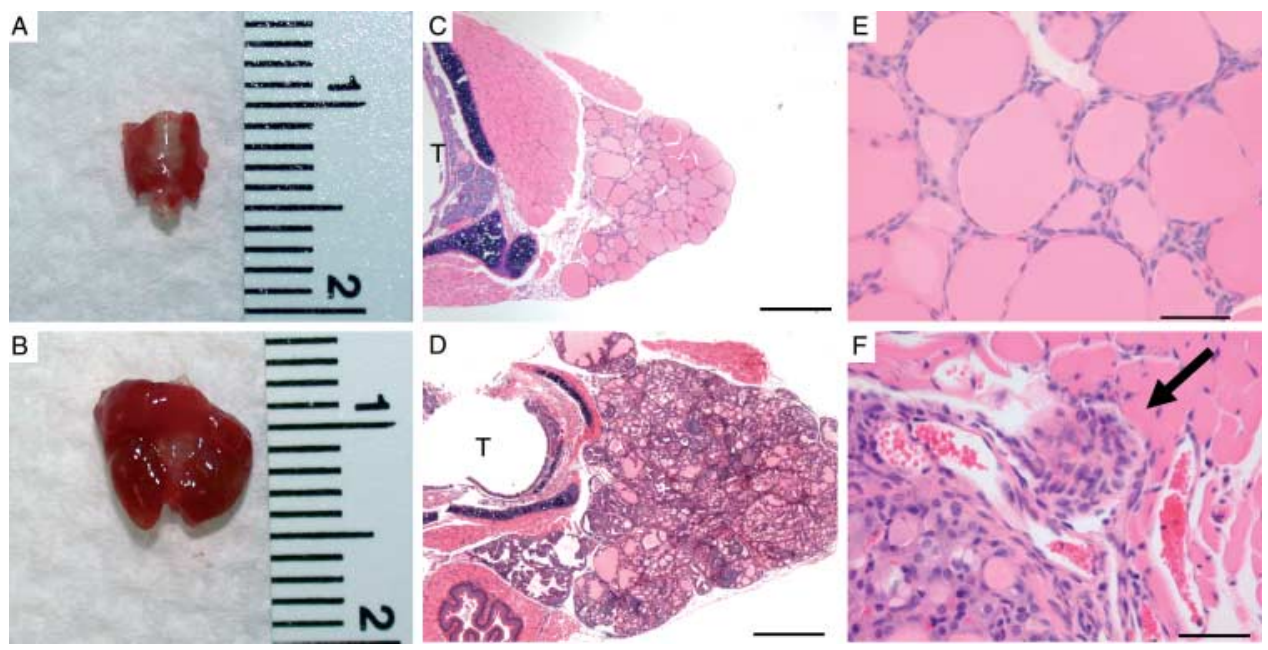

Figure 1 R1a-TpoKO thyroid tumors exhibit features of follicular thyroid carcinoma. Representative wild-type (A) and $R 1 a-T p o K O$ (B) thyroid glands at 1 year of age. Hematoxylin- and eosin-stained thyroid sections from wild-type (C and E) and $R 1 a-T p o K O$ (D and $F)$ thyroids shown at low ( $C$ and $D)$ and high ( $E$ and $F)$ magnifications. The arrow in panel $F$ indicates tumor invasion into adjacent skeletal muscle. Scale bars in C and D: $500 \mu \mathrm{m}$; scale bars in E and F: $50 \mu \mathrm{m}$. T, trachea.

Examination of the thyroids of these animals showed enlargement of the thyroids of $100 \%$ in Rla-TpoKO mice (Fig. 1A and B). At the histological level, the thyroids exhibited increased cellularity but retained a follicular pattern of growth (Fig. 1C and D). In order to determine whether the neoplastic thyroids contained foci of thyroid cancer, we studied them for the presence of cytological changes, as well as local invasiveness and distant metastasis. There were no morphologic or nuclear changes to suggest PTC in the specimens. However, we detected invasion through the thyroid capsule and in the surrounding tissues in 10/23 (43\%) of the thyroids studied (Fig. 1F). While local invasion was detected in $43 \%$ of animals, none of the tumors examined showed widely invasive or angioinvasive behavior. Examination of lymph nodes in the neck, lungs, liver, and brain failed to detect the presence of distant metastases in any tissue studied. Based on the histological data, we conclude that Rla-TpoKO mice develop FTC at a rate of $43 \%$ by 1 year of age.

\section{R1a-TpoKO tumors exhibit increased proliferation independent of the AKT and ERK pathways}

We next attempted to elucidate signaling pathways that promote tumorigenesis in this model. Because RAS/ RAF/ERK and PI3K/AKT signaling have been reported to be important tumorigenic pathways in FTC, we first attempted to determine whether these pathways were activated in the Rla-TpoKO tumors.
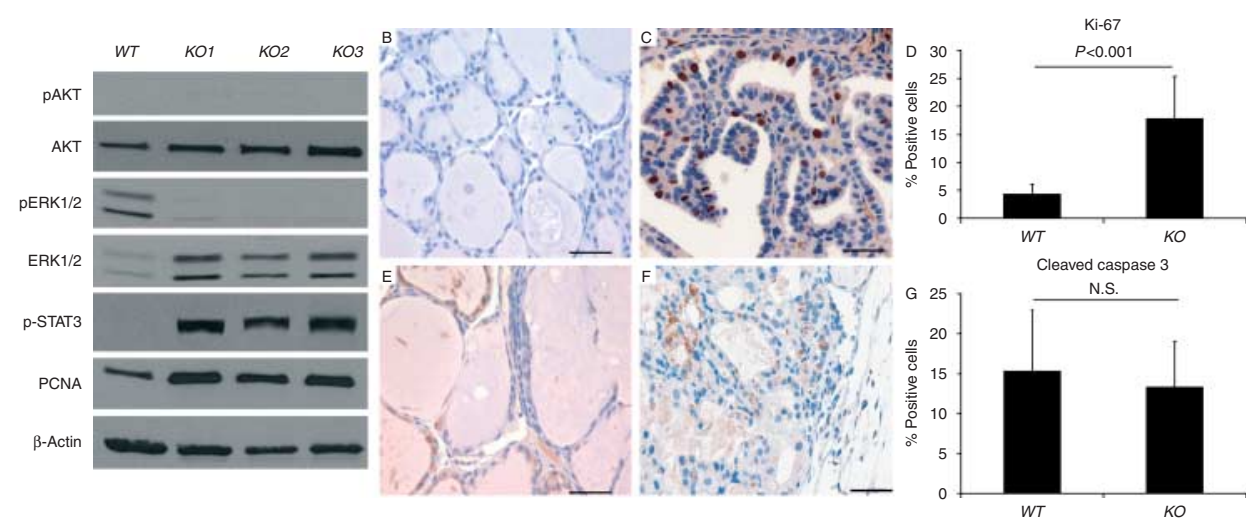

Figure 2 Proliferation is increased in R1a-TpoKO tumors. (A) Western blots of wild-type (WT) and R1a-TpoKO (KO) thyroids for the indicated proteins. Representative immunohistochemical images of WT (B) and R1a-TpoKO (C) thyroids stained for Ki-67. These results are quantified in (D). Representative immunohistochemical images of WT (E) and R1a-TpoKO (F) thyroids stained for cleaved caspase 3. These results are quantified in (G) (NS, not significant). Scale bars in all images: $50 \mu \mathrm{m}$. 
As shown in Fig. 2A, neither Akt nor Erk showed activation in these tumors, as judged by the absence of the phosphorylated (activated) isoforms of the proteins. The western blotting data were confirmed with immunohistochemical staining of tissue sections, which was also negative for the phosphorylated proteins (data not shown). In attempting to identify other pathways that may be associated with carcinogenesis, we identified activation of Stat 3 as a consistent change found in the tumors (Fig. 2A).

We also examined the proliferative and apoptotic indices of these tumors using immunohistochemical staining. Ki-67 staining showed that Rla-TpoKO tumors had a much higher number of proliferating cells than WT thyroids (Fig. 2B and C, quantified in D). We also found that cleaved caspase 3 staining of these tumors showed no change in apoptosis rates compared with WT (Fig. 2E and F, quantified in G). These results indicate that the formation of these tumors is driven primarily by an increase in proliferation and not due to a failure of apoptosis.

\section{Microarray analysis identifies enhanced proliferation and altered differentiation pathways in R1a-TpoKO tumors}

In order to further elucidate the pathways involved in tumorigenesis in this model, we performed microarray analysis on thyroids from 1-year-old WT $(n=8)$ and Rla-TpoKO $(n=8)$ animals. The complete list of genes (Supplementary Table 1, see section on supplementary data given at the end of this article) was then analyzed using IPA Software, which identified transcriptional networks altered in the tumors. Table 1 lists the four networks showing the highest scores for alterations in the tumors, and the genes that comprise each network are included in Supplementary Table 2, see section

Table 1 Top 4 altered pathways in R1a-TpoKO thyroids compared with wild-type thyroids

\begin{tabular}{|c|c|c|}
\hline Rank & Score & Pathway \\
\hline 1 & 34 & $\begin{array}{l}\text { Cell-to-cell signaling and interaction, } \\
\text { hematological system development and } \\
\text { function, immune cell trafficking }\end{array}$ \\
\hline 2 & 28 & $\begin{array}{l}\text { Cardiovascular system development and } \\
\text { function, cellular development, cellular } \\
\text { movement }\end{array}$ \\
\hline 3 & 28 & $\begin{array}{l}\text { Reproductive system development and } \\
\text { function, cellular development, cellular } \\
\text { growth and proliferation }\end{array}$ \\
\hline 4 & 26 & $\begin{array}{l}\text { Cardiovascular system development and } \\
\text { function, cancer, developmental disorder }\end{array}$ \\
\hline
\end{tabular}

on supplementary data given at the end of this article. The top 4 networks are shown as they had the highest IPA scores, with a dramatic drop in score seen for network 5. The IPA score represents the likelihood that the genes identified in the network would be found randomly (Calvano et al. 2005). In this analysis, altered cellular proliferation was identified as the third most prominent network (IPA score of 28), confirming that increased cell proliferation is the driving force in tumor growth in this model. In order to validate the microarray data, we selected eight genes that were highly altered in the Rla-TpoKO tumors and performed quantitative real-time PCR. These results confirmed the alteration of these genes indicated by the microarray (Supplementary Table 3, see section on supplementary data given at the end of this article).

Additionally, pathways related to development were associated with all the four of these highly altered networks, suggesting that differentiation may also be altered in these tumors. These data are consistent with our previously published work, which suggests that PKA is involved in differentiation and development in a number of cAMP-responsive tissues (Nadella et al. 2008, Yin et al. 2008a, Jones et al. 2010). However, genes associated with thyrocyte terminal differentiation, including thyroid peroxidase, thyroglobulin, and the sodium iodide symporter, were expressed at normal or even higher levels than WT in the RlaTpoKO tumors (Supplementary Table 4, see section on supplementary data given at the end of this article). These data highlight the fact that thyrocyte differentiation is inherently more complicated than the expression levels of these genes may indicate.

\section{Microarray analyses point to TR $\beta$ as a modulator of tumorigenesis}

In addition to the networks described earlier, the IPA analysis identified a signaling network that involved the thyroid hormone receptor $\beta$ (TR $\beta$, encoded by Thrb) (Fig. 3). Although TR $\beta$ mRNA expression was not altered in the microarray study, several genes known to be targets of TR $\beta$ signaling were identified, including mRNAs encoding the Ar, Spot14 (Thrsp), and $U c p 1$. In order to validate this result, we performed quantitative real-time PCR and western blot analyses on these targets (Fig. 4). qRT-PCR confirmed that both $A r$ and $U c p l$ were downregulated in the Rla-TpoKO thyroids compared with WT (Fig. 4A and B). Western blot analysis of Spot14 indicated a reduction and/or loss of protein expression in the Rla-TpoKO thyroids (Fig. 4C). 


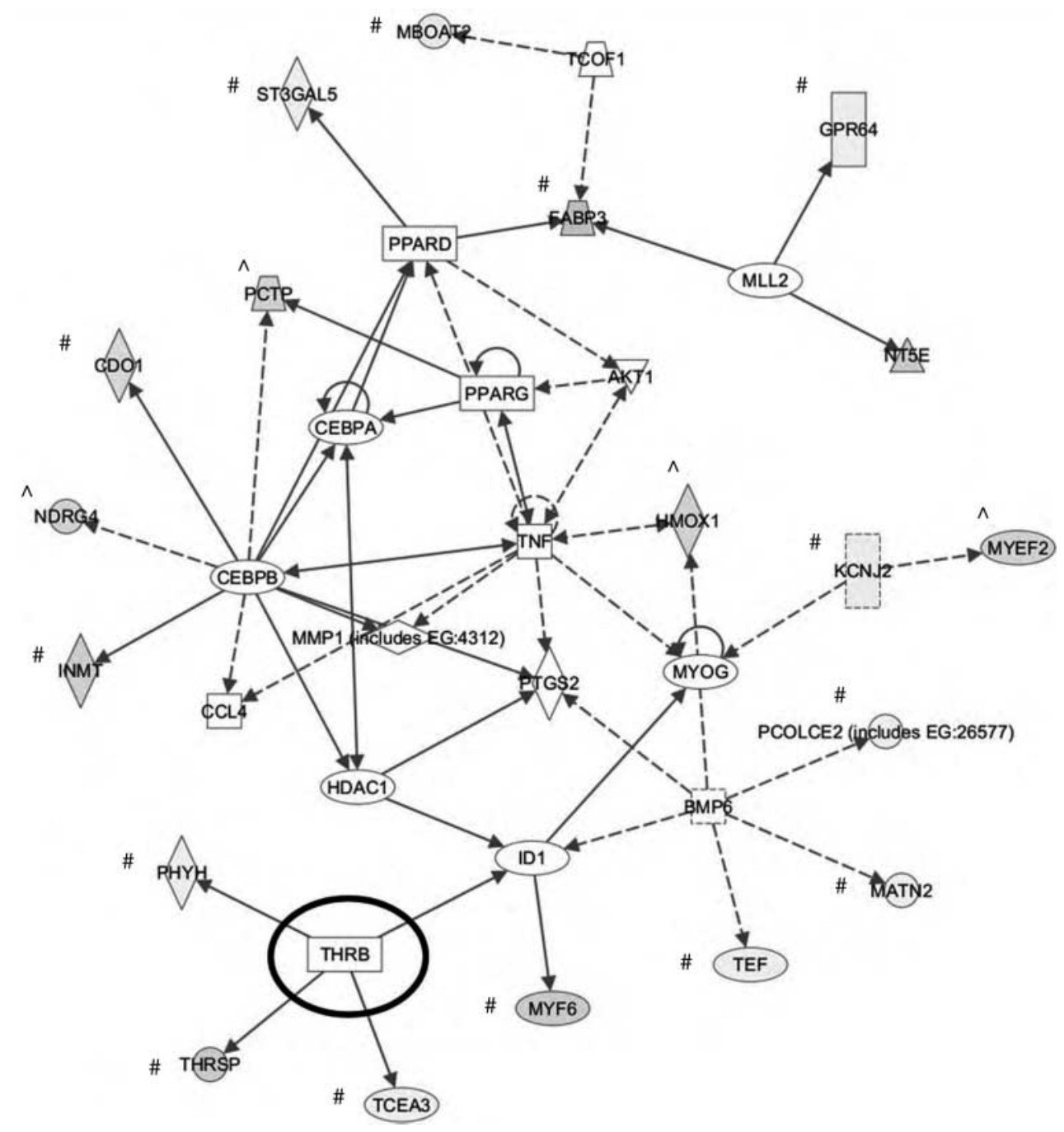

Figure 3 IPA analysis of microarray data indicates TR $\beta$ as a signaling node. IPA software indicated a network involving THRB, circled. Genes marked with ^ represent those that were upregulated according to the microarray and those marked with \# were downregulated. The intensity of the shading represents the significance of the $P$ value associated with change in expression.

\section{Primary cells cultured from R1a-TpoKO thyroids exhibit growth factor independence but require STAT3 signaling}

In order to provide an in vitro model system for the study of signaling mechanisms, we established primary cultures of cells derived from Rla-TpoKO thyroid tumors. More than $90 \%$ of cultured cells expressed thyroglobulin at a level similar to FRTL5 cells through passage 15 (Supplementary Figure 1, see section on supplementary data given at the end of this article), confirming their ability to proliferate and retain thyroid differentiation in vitro. Because WT mouse thyroid cells do not proliferate in vitro, we used the wellestablished FRTL5 rat thyroid cell line as a control for these studies (Ambesi-Impiombato et al. 1980).
Primary thyroid cultures typically require the inclusion of TSH and insulin in the medium as growth factors to enable cell proliferation. As shown in Fig. 5A, removal of TSH, insulin, or both from the medium results in significant reduction of proliferation in FRTL5 cells when compared with cells grown in complete $(6 \mathrm{H})$ medium. In contrast, Rla-TpoKO cells retained their capacity to proliferate independent of the presence of these growth factors (Fig. 5B). Expression of Tshr on both primary tumors and tumor cells grown in culture was validated (Supplementary Figure 1C) in order to confirm that this TSH-independent growth was not a consequence of loss of the receptor.

Next, we sought to assess the effects of pharmacological inhibitors on cell proliferation. Based on the 

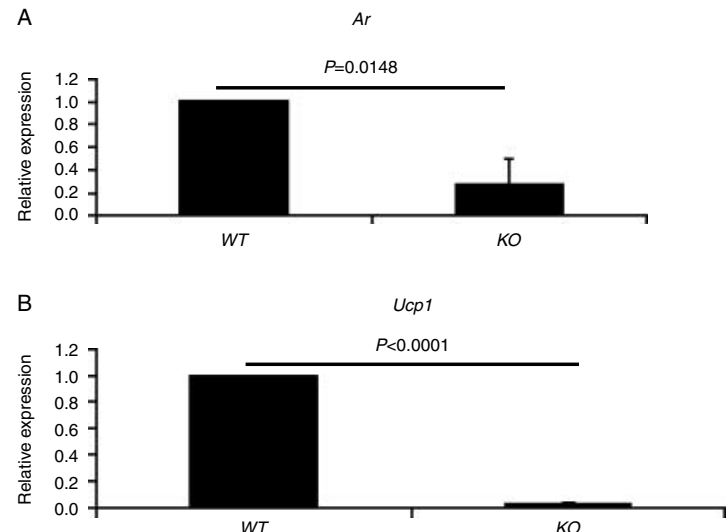

C

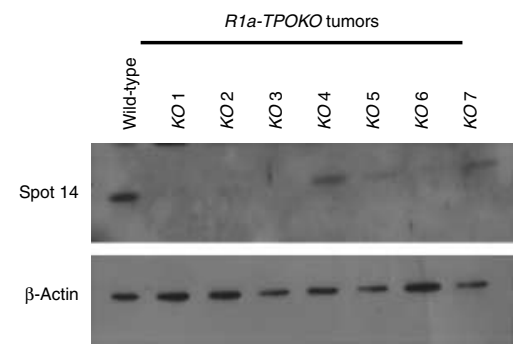

Figure 4 qRT-PCR and western blot analyses confirm possible involvement of TR $\beta$ signaling. qRT-PCR experiments of $\operatorname{Ar}(\mathrm{A})$ and $\operatorname{Ucp} 1(\mathrm{~B})$ in the R1a-TpoKO $(K O)$ thyroids compared with wild-type $(W T)$ thyroids $(n=3)$. (C) Western blot analysis of Spot14 (Thrsp) in WT and R1a-TpoKO thyroids.

data shown earlier, we hypothesized that inhibition of the AKT or MEK/ERK pathways would not lead to growth inhibition, while inhibition of PKA or STAT3 would slow cell growth. Surprisingly, LY294002, an inhibitor of AKT, significantly reduced cell proliferation compared with vehicle (Fig. 5D). Conversely, myristoylated PKI, a cell permeable specific inhibitor of PKA, failed to reduce cell growth (Fig. 5D). A novel STAT3 inhibitor, HO-3867 (Selvendiran et al. 2010) was able to significantly reduce cell proliferation at the highest dose. In order to compare our primary tumor cells with normal thyroid cells, we also examined the growth of FRTL5 cells in the presence of these inhibitors (Fig. 5C). All these inhibitors were able to inhibit growth of FRTL5 cells at the highest concentrations. Western blot analysis of pAkt, pErk, and pCreb were performed to validate the inhibition of their intended targets (Supplementary Figure 2, see section on supplementary data given at the end of this article).

In order to confirm that inhibition of cell growth by HO-3867 was due to Stat3-mediated effects, we first confirmed that treatment with HO-3867 reduces phosphorylation of Stat3 as shown in Fig. 6A.
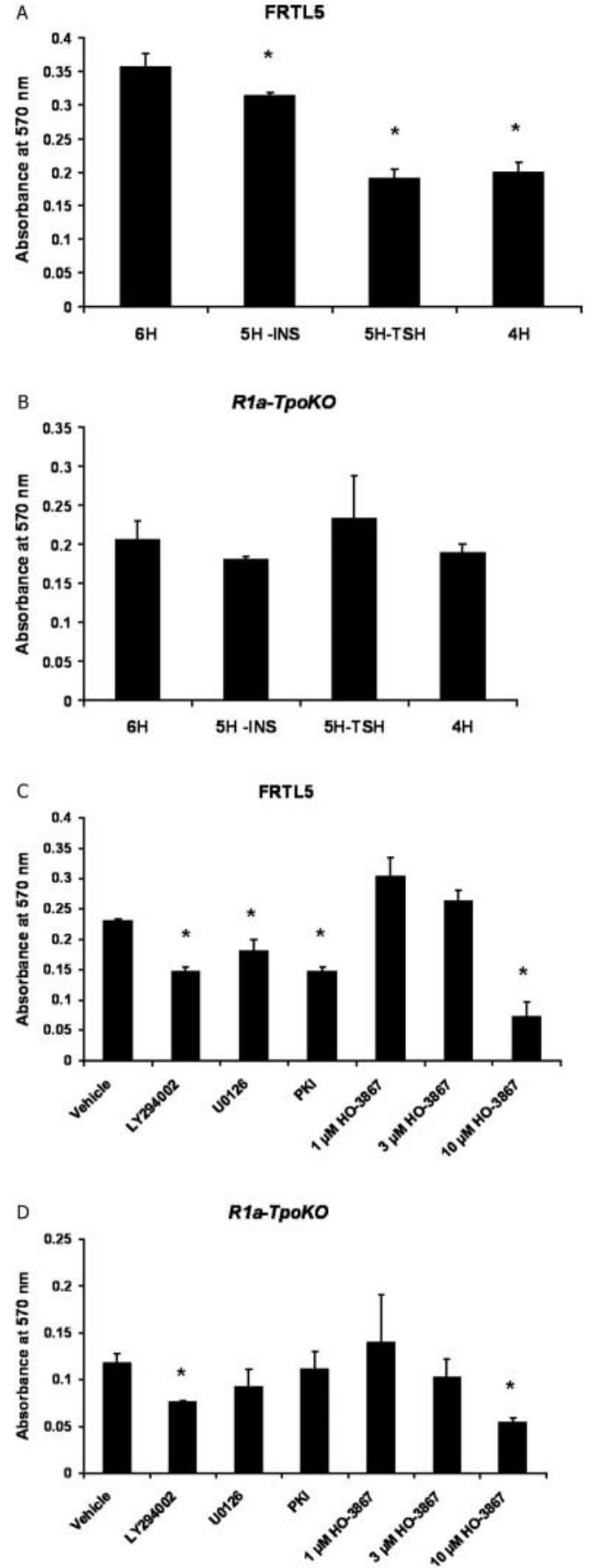

Figure 5 Cells derived from R1a-TpoKO thyroids show differing responses from normal thyroid cells in the absence of growth factors and presence of inhibitors. (A) MTT assay of FRTL5 cells, treated with indicated media, were grown in complete medium $(6 \mathrm{H})$ or in medium lacking insulin (5H-INS), TSH (5H-TSH), or both (4H). (B) R1a-TpoKO cells, treated as in A. (C) FRTL5 cells treated with the indicated inhibitors at the following concentrations: $10 \mu \mathrm{MLY} 294002,10 \mu \mathrm{M} \cup 0126,5 \mu \mathrm{M} \mathrm{PKI}$, and 1, 3, and $10 \mu \mathrm{M} \mathrm{HO}-3867$ as indicated. (D) R1a-TpoKO cells, treated as in C. In $A$ and $B,{ }^{\star} P<0.05$ compared with cells grown in $6 \mathrm{H}$ medium; in $\mathrm{C}$ and $\mathrm{D},{ }^{*} P<0.05$ compared with vehicle treatment. 

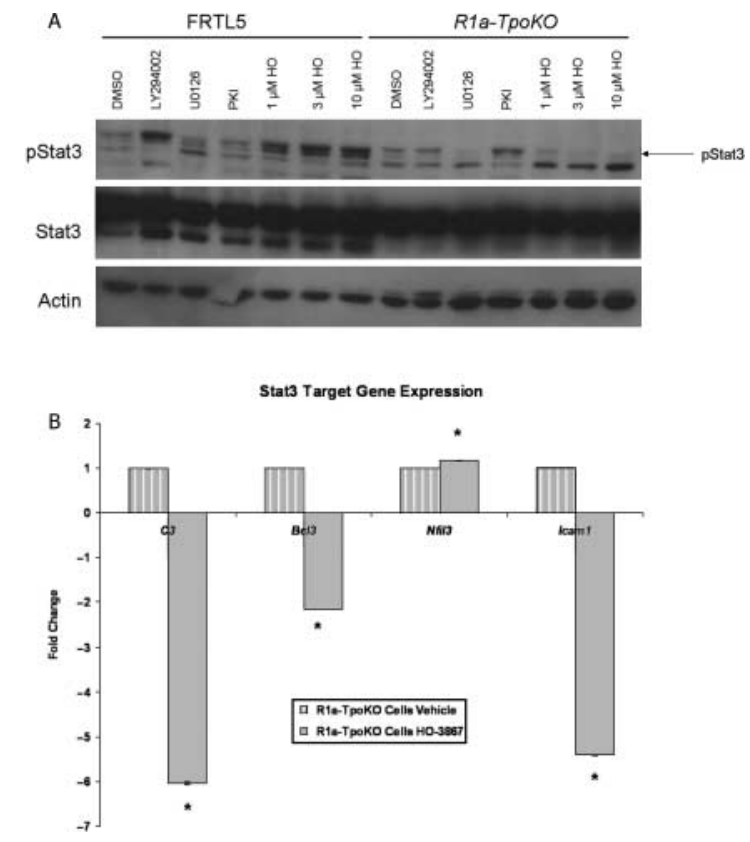

Figure 6 Treatment of R1a-TpoKO cells with a Stat3 inhibitor reduces expression of Stat3 target genes. (A) Protein lysates from FRTL5 and R1a-TpoKO cells treated with the indicated inhibitors for $48 \mathrm{~h}$ were probed with antibodies against pStat3 and Stat3 as indicated. (B) qRT-PCR experiments of $\mathrm{C} 3, \mathrm{Bc} / 3$, $\mathrm{Nfil3}$, and Icam1 in R1a-TpoKO cells treated with $\mathrm{HO}-3867$ compared with vehicle treatment. ${ }^{\star} P<0.0001$ compared with vehicle treatment.

Additionally, we performed quantitative real-time PCR analysis of known Stat3 target genes (Dauer et al. 2005). Figure 6B shows that of the four Stat3 target genes tested ( $\mathrm{C} 3, \mathrm{Bcl3}, \mathrm{Nfil3}$, and Icaml), three were significantly downregulated after $48 \mathrm{~h}$ of treatment with HO-3867 compared with cells treated with vehicle. Together, these data confirm the inhibition of Stat3's transcriptional activity by HO-3867.

\section{Discussion}

As rates of thyroid cancer continue to rise, it remains relevant to identify new murine models that can lead to insights into the mechanisms of thyroid cancer formation as well as serve as preclinical drug testing models. In this study, we observed that thyroid-specific KO of Prkarla leads to hyperthyroidism and thyroid cancer. Rla-TpoKO mice develop large tumors with $43 \%$ being classified as FTC (total $n=23$ ). Notably, no distant metastases were seen in any of our animals, suggesting that another genetic mutation may be necessary to elicit metastases in the context of Prkarla mutation in the thyroid.

It is well known that TSH stimulates PKA activity via activation of adenylyl cyclase and the production of cAMP. Additionally, elevated levels of TSH are also known to be associated with the development of thyroid cancer in humans (Hargadine et al. 1970, Haymart et al. 2008). However, a mouse model of elevated TSH signaling in a genetically WT background does not develop thyroid cancer (Brewer et al. 2007). The reason behind this discrepancy between mice and humans remains to be determined, and PKA activity has not been directly examined in the previously mentioned model of elevated TSH. In contrast to elevated TSH levels leading to increased PKA signaling, our mice are hyperthyroid, exhibiting low levels of TSH along with activated PKA. These data suggest that TSH signaling may also activate alternate pathways that provide negative feedback on cell growth. This hypothesis may explain why mice with PKA activation develop FTC, while tumors driven by elevated TSH do not develop cancers.

It is interesting to note that ablation of PRKARIA/ Prkarla from the thyroid is the only genetic change described to date, which produces FTC in both humans and mice. There have been other mouse lines made to generate FTC; however, none of these models mimic both the genetics and phenotypes seen in humans. PTEN mutations have been described in patients with FTC, but the mouse model harboring a deletion of Pten in the thyroid does not develop FTC and instead exhibits thyroid hyperplasia (Yeager et al. 2007). We have also recapitulated this data in our laboratory (data not shown). A small number of FTC patients exhibit mutations in RAS (Niepomniszcze et al. 2006); however, mice expressing the oncogenic allele of Kras in the thyroid show no thyroid abnormalities up to 1 year of age (Miller et al. 2009). In contrast, mice harboring a Pten deletion as well as an oncogenic allele of Kras in the thyroid develop aggressive FTC and lung metastases (Miller et al. 2009), which supports our hypothesis that more than one genetic alteration may be necessary to elicit metastatic thyroid cancer. The mouse expressing a transgene of the PAX8-PPARG fusion protein in the thyroid also fails to develop the FTC seen in patients harboring this genetic translocation (Diallo-Krou et al. 2009). Similar to the Kras mouse model, it has very recently been shown that mice harboring both the PAX8-PPARG fusion protein and Pten deletion in the thyroid develop aggressive and metastatic FTC (Dobson et al. 2011), again indicating that multiple genetic hits are necessary for FTC progression to metastatic disease.

The only other previously published mouse model of FTC, which does develop aggressive FTC, harbors a mutation in Thrb known as the PV mutation $\left(T h r b^{P V / P V}\right.$ ) (Kato et al. 2004). However, mutations 
in THRB in human patients have, to date, only been seen in patients presenting with thyroid hormone resistance and not FTC (Rocha et al. 2007). Interestingly, $T h r b^{P V / P V}$ mice exhibit strikingly high levels of TSH. Thus, the possibility of PKA driving tumor formation in these animals cannot be ruled out. While the effects of TSH stimulation vs the effects of the Thrb mutation on thyrocyte proliferation in this model have been initially examined ( $\mathrm{Lu}$ et al. 2011), it is still unclear what role the activation of PKA, if any, plays in this model.

Although THRB may not be a tumor suppressor gene in humans, our microarray data support the hypothesis that TR $\beta$ may play a role in tumorigenesis in the thyroid. IPA analyses of this data pointed to an altered signaling network involving TR $\beta$ (Fig. 3). Interestingly, it has been shown that Spot14 and Ucpl mRNA and protein as well as Ar levels increase in a hyperthyroid state or after administration of thyroid hormone to hypothyroid mice and rats (Narayan \& Towle 1985, Kinlaw et al. 1989, Lee et al. 2007, Martinez de Mena et al. 2010). However, in our animals, the levels of all the three mRNAs and the levels of Spot14 protein dramatically decreased, converse to the expected increases in a hyperthyroid animal. Although the mechanisms of action still require more research, our data indicate that elevated PKA signaling may lead to alteration of TR $\beta$ 's normal transcriptional activity, which suggests that the importance of TR $\beta$ in FTC development may lie in modulation of its transcriptional activity by other molecules. While these hypotheses require further experimentation, we believe that our data together suggest that PKA has effects on TR $\beta$ transcriptional function, which may shed light on how elevated TSH levels lead to FTC formation in humans.

The RAS/RAF/MEK/ERK and PI3K/AKT pathways have long been thought to be major players in the development of FTC (reviewed in Brzezianska \& Pastuszak-Lewandoska (2011)); however, our data suggest that this may not be the case, as we have shown FTC formation in the absence of activated Erk or Akt. These data are consistent with our previously published data in both mouse embryonic fibroblasts and Schwann cells, which shows that cellular proliferation in the context of elevated PKA activity is independent of Erk and Akt (Nadella \& Kirschner 2005, Jones et al. 2008).

Surprisingly, inhibition of AKT proved to decrease in vitro proliferation of these cells. While this result seems contradictory to our in vivo data, Supplementary Figure 2 shows that once in culture, these cells do show activation of Akt and Erk, indicating an alteration in signaling compared with the in vivo tumors. While these results suggest that this culture system does not perfectly mimic the in vivo tumor conditions, these cells still provide a unique setting for studying the molecular mechanisms of FTC.

In contrast to Akt and Erk, Stat3 was shown to be highly activated in tumors as well as the cultured cells (Fig. 2 and Supplementary Figure 2). Inhibition of Stat3 with HO-3867 did show a significant reduction in cell growth in these cells. Additionally, our quantitative real-time PCR data indicate that this growth inhibition is mediated by effects on Stat3, as treatment of cells with HO-3867 leads to a reduction of mRNA levels of several Stat3 target genes (Fig. 6). While the mRNA levels of Nfil3 were found to be slightly upregulated, this could be due to other regulatory elements on the promoter of this gene as $N f i l 3$ has been shown to be sensitive to levels of insulin and subsequent Akt activation (Tong et al. 2010). As our in vitro data suggest that the tumor cells are dependent on Akt in culture, this may explain the lack of downregulation of $N f i l 3$ upon treatment with HO-3867. While it is impossible to fully rule out off-target effects of this inhibitor, we believe that, together, our data suggest a possible role for Stat 3 in the development of FTC in this mouse model.

STAT3 has been implicated in progression and metastases of papillary, anaplastic, and medullary thyroid cancer (Hwang et al. 2003, Trovato et al. 2003, Plaza-Menacho et al. 2007, Kim et al. 2009), but its implications in FTC are not well described. Trovato et al. (2003) described activated STAT3 as only occurring in PTC and not any of a large set of FTC that was examined. To our knowledge, our mouse model is the only report of activated Stat 3 in FTC. Recent work has also shown that nuclear Jak2 enhances the stability of activated Creb in the mouse and rat adrenal gland (Lefrancois-Martinez et al. 2011), suggesting that the JAK/STAT pathway may be linked to PKA in endocrine tissues.

Taken together, these data indicate that Prkarla is indeed a tumor suppressor in the thyroid and that loss of this gene leads to hyperthyroidism and FTC. Our model is the first described model of FTC that is independent of Akt and develops FTC while engineered to harbor a single genetic alteration known to be associated with FTC in humans. In summary, we believe that this mouse is a novel and highly reproducible model of FTC, which may help to elucidate how the TSH/PKA signaling axis contributes to the development of thyroid cancer as well as suggesting new targets, such as STAT3, for the development of FTC therapies. 


\section{Supplementary data}

This is linked to the online version of the paper at http://dx. doi.org/10.1530/ERC-11-0306.

\section{Declaration of interest}

The authors declare that there is no conflict of interest that could be perceived as prejudicing the impartiality of the research reported.

\section{Funding}

This work was supported in part by NIH grants: CA112268 (L S Kirschner), PO1CA124570 (D R Pringle, L Yu, D Jarjoura, K M D La Perle, and L S Kirschner), and CA16058 (to the OSU Comprehensive Cancer Center). D R Pringle was supported by the Jeffrey J Seilhamer Memorial Fellowship.

\section{Acknowledgements}

The authors would like to acknowledge Alan Flechtner, HTL (ASCP) of the Ohio State University College of Veterinary Medicine Comparative Pathology and Mouse Phenotyping Core, for his help with processing, sectioning, and staining tissues for this study; Lisa Rawahneh, Ohio State University Comprehensive Cancer Center, for her assistance in sectioning and $\mathrm{H} / \mathrm{E}$ staining. They also thank Motoyasu Saji, MD, PhD, Ohio State University, Division of Internal Medicine, for his valuable technical assistance in establishing primary thyroid cell cultures. Additionally, they would like to acknowledge Periannan Kuppusamy, PhD and Brian Rivera of the Davis Heart and Lung Research Institute, The Ohio State University, for providing us with the HO-3867 compound.

\section{References}

Ambesi-Impiombato FS, Parks LA \& Coon HG 1980 Culture of hormone-dependent functional epithelial cells from rat thyroids. PNAS 77 3455-3459. (doi:10.1073/pnas.77.6. 3455)

Aschebrook-Kilfoy B, Ward MH, Sabra MM \& Devesa SS 2010 Thyroid cancer incidence patterns in the United States by histologic type, 1992-2006. Thyroid 21 125-134. (doi:10.1089/thy.2010.0021)

Bertherat J, Horvath A, Groussin L, Grabar S, Boikos S, Cazabat L, Libe R, Rene-Corail F, Stergiopoulos S, Bourdeau I et al. 2009 Mutations in regulatory subunit type $1 \mathrm{~A}$ of cyclic adenosine $5^{\prime}$-monophosphate-dependent protein kinase (PRKAR1A): phenotype analysis in 353 patients and 80 different genotypes. Journal of Clinical Endocrinology and Metabolism 94 2085-2091. (doi:10.1210/jc.2008-2333)

Besic N, Auersperg M \& Golouh R 1999 Prognostic factors in follicular carcinoma of the thyroid - a multivariate survival analysis. European Journal of Surgical Oncology 25 599-605. (doi:10.1053/ejso.1999.0714)
Brewer C, Yeager N \& Di Cristofano A 2007 Thyroidstimulating hormone initiated proliferative signals converge in vivo on the mTOR kinase without activating AKT. Cancer Research 67 8002-8006. (doi:10.1158/ 0008-5472.CAN-07-2471)

Brzezianska E \& Pastuszak-Lewandoska D 2011 A minireview: the role of MAPK/ERK and PI3K/Akt pathways in thyroid follicular cell-derived neoplasm. Frontiers in Bioscience 16 422-439. (doi:10.2741/3696)

Calvano SE, Xiao W, Richards DR, Felciano RM, Baker HV, Cho RJ, Chen RO, Brownstein BH, Cobb JP, Tschoeke SK et al. 2005 A network-based analysis of systemic inflammation in humans. Nature 437 1032-1037. (doi:10.1038/nature03985)

Dauer DJ, Ferraro B, Song L, Yu B, Mora L, Buettner R, Enkemann S, Jove R \& Haura EB 2005 Stat3 regulates genes common to both wound healing and cancer. Oncogene 24 3397-3408. (doi:10.1038/sj.onc.1208469)

Diallo-Krou E, Yu J, Colby LA, Inoki K, Wilkinson JE, Thomas DG, Giordano TJ \& Koenig RJ 2009 Paired box gene 8-peroxisome proliferator-activated receptor- $\gamma$ fusion protein and loss of phosphatase and tensin homolog synergistically cause thyroid hyperplasia in transgenic mice. Endocrinology 150 5181-5190. (doi:10.1210/en. 2009-0701)

Dobson ME, Diallo-Krou E, Grachtchouk V, Yu J, Colby LA, Wilkinson JE, Giordano TJ \& Koenig RJ 2011

Pioglitazone induces a proadipogenic antitumor response in mice with PAX8-PPAR $\gamma$ fusion protein thyroid carcinoma. Endocrinology 152 4455-4465. (doi:10.1210/ en.2011-1178)

Gordon A, Glazko G, Qiu X \& Yakovlev A 2007 Control of the mean number of false discoveries, Bonferroni and stability of multiple testing. Annals of Applied Statistics 1 179-190. (doi:10.1214/07-AOAS102)

Hargadine HR, Lowenstein JM \& Greenspan FS 1970 Elevated serum TSH in human thyroid cancer. Oncology 24 172-180. (doi:10.1159/000224517)

Haymart MR, Repplinger DJ, Leverson GE, Elson DF, Sippel RS, Jaume JC \& Chen H 2008 Higher serum thyroid stimulating hormone level in thyroid nodule patients is associated with greater risks of differentiated thyroid cancer and advanced tumor stage. Journal of Clinical Endocrinology and Metabolism 93 809-814. (doi:10.1210/jc.2007-2215)

Hollander MC, Blumenthal GM \& Dennis PA 2011 PTEN loss in the continuum of common cancers, rare syndromes and mouse models. Nature Reviews Cancer 11 289-301. (doi:10.1038/nrc3037)

Hwang JH, Kim DW, Suh JM, Kim H, Song JH, Hwang ES, Park KC, Chung HK, Kim JM, Lee TH et al. 2003 Activation of signal transducer and activator of transcription 3 by oncogenic RET/PTC (rearranged in transformation/papillary thyroid carcinoma) tyrosine kinase: roles in specific gene regulation and cellular transformation. Molecular Endocrinology 17 1155-1166. (doi:10.1210/me.2002-0401) 
Irizarry RA, Hobbs B, Collin F, Beazer-Barclay YD, Antonellis KJ, Scherf U \& Speed TP 2003 Exploration, normalization, and summaries of high density oligonucleotide array probe level data. Biostatistics 4 249-264. (doi:10.1093/biostatistics/4.2.249)

Jeker LT, Hejazi M, Burek CL, Rose NR \& Caturegli P 1999 Mouse thyroid primary culture. Biochemical and Biophysical Research Communications 257 511-515. (doi:10.1006/bbrc.1999.0468)

Jones GN, Tep C, Towns WH II, Mihai G, Tonks ID, Kay GF, Schmalbrock PM, Stemmer-Rachamimov AO, Yoon SO \& Kirschner LS 2008 Tissue-specific ablation of Prkar1a causes schwannomas by suppressing neurofibromatosis protein production. Neoplasia 10 1213-1221. (doi:10. 1593/neo.08652)

Jones GN, Pringle DR, Yin Z, Carlton MM, Powell KA, Weinstein MB, Toribio RE, La Perle KM \& Kirschner LS 2010 Neural crest-specific loss of Prkar1a causes perinatal lethality resulting from defects in intramembranous ossification. Molecular Endocrinology 24 1559-1568. (doi:10.1210/me.2009-0439)

Kato Y, Ying H, Willingham MC \& Cheng SY 2004 A tumor suppressor role for thyroid hormone $\beta$ receptor in a mouse model of thyroid carcinogenesis. Endocrinology 145 4430-4438. (doi:10.1210/en.2004-0612)

Kim TH, Lee SY, Rho JH, Jeong NY, Soung YH, Jo WS, Kang DY, Kim SH \& Yoo YH 2009 Mutant p53 (G199V) gains antiapoptotic function through signal transducer and activator of transcription 3 in anaplastic thyroid cancer cells. Molecular Cancer Research 7 1645-1654. (doi:10.1158/1541-7786.MCR-09-0117)

Kinlaw WB, Ling NC \& Oppenheimer JH 1989 Identification of rat $\mathrm{S} 14$ protein and comparison of its regulation with that of mRNA S14 employing synthetic peptide antisera. Journal of Biological Chemistry 264 19779-19783.

Kirschner LS, Sandrini F, Monbo J, Lin JP, Carney JA \& Stratakis CA 2000 Genetic heterogeneity and spectrum of mutations of the PRKAR1A gene in patients with the Carney complex. Human Molecular Genetics 9 3037-3046. (doi:10.1093/hmg/9.20.3037)

Kirschner LS, Kusewitt DF, Matyakhina L, Towns WH II, Carney JA, Westphal H \& Stratakis CA 2005 A mouse model for the Carney complex tumor syndrome develops neoplasia in cyclic AMP-responsive tissues. Cancer Research 65 4506-4514. (doi:10.1158/0008-5472. CAN-05-0580)

Kusakabe T, Kawaguchi A, Kawaguchi R, Feigenbaum L \& Kimura S 2004 Thyrocyte-specific expression of Cre recombinase in transgenic mice. Genesis 39 212-216. (doi:10.1002/gene.20043)

Lacroix L, Lazar V, Michiels S, Ripoche H, Dessen P, Talbot M, Caillou B, Levillain JP, Schlumberger M \& Bidart JM 2005 Follicular thyroid tumors with the PAX8-PPAR $\gamma 1$ rearrangement display characteristic genetic alterations. American Journal of Pathology 167 223-231. (doi:10.1016/S0002-9440(10)62967-7)
Lee E, Ahn MY, Kim HJ, Kim IY, Han SY, Kang TS, Hong JH, Park KL, Lee BM \& Kim HS 2007 Effect of di(n-butyl) phthalate on testicular oxidative damage and antioxidant enzymes in hyperthyroid rats. Environmental Toxicology 22 245-255. (doi:10.1002/tox.20259)

Lefrancois-Martinez AM, Blondet-Trichard A, Binart N, Val P, Chambon C, Sahut-Barnola I, Pointud JC \& Martinez A 2011 Transcriptional control of adrenal steroidogenesis: novel connection between JAK2 and PKA through stabilization of transcription factor CREB. Journal of Biological Chemistry 286 32976-32985. (doi:10.1074/jbc. M111.218016)

Lu C, Zhu X, Willingham MC \& Cheng SY 2011 Activation of tumor cell proliferation by thyroid hormone in a mouse model of follicular thyroid carcinoma. Oncogene 31 2007-2016. (doi:10.1038/onc.2011.390)

Martinez de Mena R, Scanlan TS \& Obregon MJ 2010 The T3 receptor $\beta 1$ isoform regulates UCP1 and D2 deiodinase in rat brown adipocytes. Endocrinology 151 5074-5083. (doi:10.1210/en.2010-0533)

Miller KA, Yeager N, Baker K, Liao XH, Refetoff S \& Di Cristofano A 2009 Oncogenic Kras requires simultaneous PI3K signaling to induce ERK activation and transform thyroid epithelial cells in vivo. Cancer Research 69 3689-3694. (doi:10.1158/0008-5472. CAN-09-0024)

Nadella KS \& Kirschner LS 2005 Disruption of protein kinase A regulation causes immortalization and dysregulation of D-type cyclins. Cancer Research 65 10307-10315. (doi:10.1158/0008-5472.CAN-05-3183)

Nadella KS, Jones GN, Trimboli A, Stratakis CA, Leone G \& Kirschner LS 2008 Targeted deletion of Prkarla reveals a role for protein kinase A in mesenchymal-to-epithelial transition. Cancer Research 68 2671-2677. (doi:10.1158/ 0008-5472.CAN-07-6002)

Nagy R, Ganapathi S, Comeras I, Peterson C, Orloff M, Porter K, Eng C, Ringel MD \& Kloos RT 2011 Frequency of germline PTEN mutations in differentiated thyroid cancer. Thyroid 21 505-510. (doi:10.1089/thy.2010.0365)

Narayan P \& Towle HC 1985 Stabilization of a specific nuclear mRNA precursor by thyroid hormone. Molecular and Cellular Biology 5 2642-2646. (doi:10.1128/MCB.5. 10.2642)

Niepomniszcze H, Suarez H, Pitoia F, Pignatta A, Danilowicz K, Manavela M, Elsner B \& Bruno OD 2006 Follicular carcinoma presenting as autonomous functioning thyroid nodule and containing an activating mutation of the TSH receptor (T620I) and a mutation of the Ki-RAS (G12C) genes. Thyroid 16 497-503. (doi:10.1089/thy.2006.16.497)

Nikiforov YE 2011 Molecular diagnostics of thyroid tumors. Archives of Pathology \& Laboratory Medicine 135 569-577.

Plaza-Menacho I, van der Sluis T, Hollema H, Gimm O, Buys CH, Magee AI, Isacke CM, Hofstra RM \& Eggen BJ 2007 Ras/ERK1/2-mediated STAT3 Ser727 phosphorylation by familial medullary thyroid carcinoma-associated RET 
mutants induces full activation of STAT3 and is required for c-fos promoter activation, cell mitogenicity, and transformation. Journal of Biological Chemistry $\mathbf{2 8 2}$ 6415-6424. (doi:10.1074/jbc.M608952200)

Rocha AS, Marques R, Bento I, Soares R, Magalhaes J, de Castro IV \& Soares P 2007 Thyroid hormone receptor $\beta$ mutations in the 'hot-spot region' are rare events in thyroid carcinomas. Journal of Endocrinology 192 83-86. (doi:10.1677/JOE-06-0009)

Sandrini F, Matyakhina L, Sarlis NJ, Kirschner LS, Farmakidis C, Gimm O \& Stratakis CA 2002 Regulatory subunit type I- $\alpha$ of protein kinase A (PRKAR1A): a tumor-suppressor gene for sporadic thyroid cancer. Genes, Chromosomes \& Cancer 35 182-192. (doi:10.1002/gcc.10112)

Sartor MA, Tomlinson CR, Wesselkamper SC, Sivaganesan S, Leikauf GD \& Medvedovic M 2006 Intensity-based hierarchical Bayes method improves testing for differentially expressed genes in microarray experiments. BMC Bioinformatics 7 538. (doi:10.1186/1471-2105-7-538)

Selvendiran K, Ahmed S, Dayton A, Kuppusamy ML, Tazi M, Bratasz A, Tong L, Rivera BK, Kalai T, Hideg K et al. 2010 Safe and targeted anticancer efficacy of a novel class of antioxidant-conjugated difluorodiarylidenyl piperidones: differential cytotoxicity in healthy and cancer cells. Free Radical Biology \& Medicine 48 1228-1235. (doi:10.1016/j.freeradbiomed.2010.02.009)

Stratakis CA, Kirschner LS \& Carney JA 2001 Clinical and molecular features of the Carney complex: diagnostic criteria and recommendations for patient evaluation. Journal of Clinical Endocrinology and Metabolism 86 4041-4046. (doi:10.1210/jc.86.9.4041)

Tong X, Muchnik M, Chen Z, Patel M, Wu N, Joshi S, Rui L, Lazar MA \& Yin L 2010 Transcriptional repressor E4binding protein 4 (E4BP4) regulates metabolic hormone fibroblast growth factor 21 (FGF21) during circadian cycles and feeding. Journal of Biological Chemistry 285 36401-36409. (doi:10.1074/jbc.M110.172866)

Trovato M, Grosso M, Vitarelli E, Ruggeri RM, Alesci S, Trimarchi F, Barresi G \& Benvenga S 2003 Distinctive expression of STAT3 in papillary thyroid carcinomas and a subset of follicular adenomas. Histology and Histopathology 18 393-399.

Yeager N, Klein-Szanto A, Kimura S \& Di Cristofano A 2007 Pten loss in the mouse thyroid causes goiter and follicular adenomas: insights into thyroid function and Cowden disease pathogenesis. Cancer Research 67 959-966. (doi:10.1158/0008-5472.CAN-06-3524)

Yin Z, Jones GN, Towns WH II, Zhang X, Abel ED, Binkley PF, Jarjoura D \& Kirschner LS $2008 a$ Heart-specific ablation of Prkarla causes failure of heart development and myxomagenesis. Circulation 117 1414-1422. (doi:10.1161/CIRCULATIONAHA. 107.759233)

Yin Z, Williams-Simons L, Parlow AF, Asa S \& Kirschner LS $2008 b$ Pituitary-specific knockout of the Carney complex gene Prkar1a leads to pituitary tumorigenesis. Molecular Endocrinology 22 380-387. (doi:10.1210/me. 2006-0428)

Yu LB, Gulati P, Fernandez S, Pennell M, Kirschner L \& Jarjoura D 2011 Fully moderated T-statistic for small sample size gene expression arrays. Statistical Applications in Genetics and Molecular Biology 1042. (doi:10.2202/1544-6115.1701)

Received in final form 14 March 2012 Accepted 17 April 2012 Made available online as an Accepted Preprint 18 April 2012 